\title{
Chapter 2 \\ A Greeting from Hamburg to the Otto Stern Symposium
}

\author{
Peter E. Toschek
}

Dear Chairmen Profs. Herschbach and Toennies, dear organizers Profs. SchmidtBöcking and Friedrich, dear Colleagues, dear Ladies and Gentlemen.

The occasion for our gathering today in this location is a truly historic one: the centenary of the first quantitative experiment with molecular beams, a technique that would enable, in 1922, the first convincing proof of quantum mechanics - the fundamental theory of light and matter - and to give due honor to the pioneer physicist who developed this technique: Otto Stern.

It is my pleasant duty to congratulate, in the name of the Akademie der Wissenschaften in Hamburg and in my own name, our Frankfurt colleagues and the Johann-Wolfgang-Goethe-Universität to this most appropriate and promising event.

Otto Stern's and Walther Gerlach's ground-breaking experiment-the detection of the "Richtungsquantelung" (space quantization) of atoms in a magnetic field-was spectacularly performed here in Frankfurt. Fortunately enough, the founding fathers of Hamburg University - that celebrates its centenary this year as well—recognized Stern's brilliance and awarded him the Chair of Physical Chemistry in 1923. Highlights of his and his team's activities in the following decade included such fundamental discoveries as the verification of de Broglie's matter waves, the measurement of proton's magnetic moment, which is the first measurement of a nuclear quantity, and the demonstration of recoil of atoms upon emission and absorption of light- the first requirement for the much later ubiquitous laser cooling of atoms. The key to these magnificent achievements was the further exploitation of Stern's molecular beam technique that allows to control two atomic translational degrees of freedom. The step towards a 3-D control of atomic motion, forming what could be called a "zero-dimensional atomic beam," is a precondition for making the atom available for

The author died on 25 June 2020.

P. E. Toschek $(\bowtie)$

Institut für Laserphysik, Universität Hamburg, Hamburg, Germany

B. Friedrich and H. Schmidt-Böcking (eds.), Molecular Beams in Physics and Chemistry, https://doi.org/10.1007/978-3-030-63963-1_2 
manipulation over long time durations. It took half a century for this advancement to be achieved.

In 1933, at the zenith of his career, Otto Stern had to face callous rejection and horrible injustice. Both centers of his prolific scientific activity-Frankfurt and Hamburg - have many good reasons to remember and to highlight this giant of physics, his multi-facetted achievements, and the wide-ranging consequences of his ideas.

The Board and the Members of the Akademie der Wissenschaften in Hamburg extend their most sincere wishes to speakers, guests, and organizers for a most successful and inspiring Symposium, commensurate with the innovative and communicative spirit of Otto Stern.

Frankfurt, 1 September 2019

Open Access This chapter is licensed under the terms of the Creative Commons Attribution 4.0 International License (http://creativecommons.org/licenses/by/4.0/), which permits use, sharing, adaptation, distribution and reproduction in any medium or format, as long as you give appropriate credit to the original author(s) and the source, provide a link to the Creative Commons license and indicate if changes were made.

The images or other third party material in this chapter are included in the chapter's Creative Commons license, unless indicated otherwise in a credit line to the material. If material is not included in the chapter's Creative Commons license and your intended use is not permitted by statutory regulation or exceeds the permitted use, you will need to obtain permission directly from the copyright holder. 